\title{
Techno-economic study of a hybrid power generation system at the Lebanese coastal highways
}

\author{
Mohammad Hammoud ${ }^{1}$, Jaafar Hallal ${ }^{2}$, Tala Moussa ${ }^{3}$, Hussein Kassem ${ }^{4}$ \\ ${ }^{1,2,4}$ SDM Research Group, International University of Beirut (BIU), Beirut, Lebanon \\ ${ }^{1,4}$ Department of Mechanical Engineering, Lebanese International University (LIU), Bekaa, Lebanon \\ ${ }^{2}$ Faculty of Engineering, Lebanese University, Beirut, Lebanon \\ ${ }^{3}$ MAtériaux et Ingénierie Mécanique (MATIM), Université de Reims Champagne-Ardenne (URCA), Reims, France
}

\begin{tabular}{l}
\hline \hline Article Info \\
\hline Article history: \\
Received Sep 10, 2021 \\
Revised Sep 30, 2021 \\
Accepted Nov 3, 2021
\end{tabular}

Keywords:

Coastal highway

Environment

Green energy

Photovoltaic

RETScreen

Wind energy

\begin{abstract}
Despite its great importance in daily life, electricity remains one of the most critical issues in Lebanon where the power supply has been erratic for years and the government faces numerous problems in buying foreign currency for fuel import from petroleum countries. Therefore, there is an urgent need for efficient solutions to produce local energy in a more sustainable way, leading to an environmentally friendly energy consumption, far away from conventional energy sources. In this work, unconventional technologies are used for the generation of clean energy from a system of photovoltaic (PV) panels and wind turbines. The novelty lies in the fact that the cost of the land required for the installation is almost zero. The middle of the highways is usually left unoccupied and therefore suitable for the project. Another innovative feature of the proposed system is its ability to be connected to the public utility without the need for battery storage, which reduces the total cost of the system. The proposed design consists of 87,750 PVs arranged in pairs on a steel frame for a coastal distance of 117,000 meters (highway distance between Tyre and Tripoli) with a width of 2 meters and 29,250 vertical wind turbines placed under the chassis. Using RETScreen software, the capacity of the resulting system is estimated at $39.9 \mathrm{GW} /$ year. The system would lead to a reduction in $\mathrm{CO}_{2}$ and $\mathrm{GHG}$ emissions of approximately $28,211 \mathrm{tCO}_{2}$ /year. The payback period of this project is estimated at 9 years with a lifetime of 25 years.
\end{abstract}

This is an open access article under the CC BY-SA license.

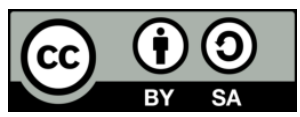

\section{Corresponding Author: \\ Mohammad Hammoud \\ SDM Research Group \\ International University of Beirut (BIU) \\ Beirut, Lebanon \\ Department of Mechanical Engineering \\ Lebanese International University (LIU) \\ Bekaa, Lebanon \\ Email: mohamad.hammoud@liu.edu.lb}

\section{INTRODUCTION}

High-quality, low-cost energy has recently become the primary concern of nations around the world and the key to the control and management of all sectors, including industrial production, buildings, agriculture and manufacturing. For centuries, energy production has been based on conventional resources such as fossil fuels (FF) and coal. However, due to the higher increase in population and energy demand, attention is now turning to new green resources that have a low environmental impact and do not release 
toxic substances into the environment that affect both the quality of the environment and the health and safety of people.

Unfortunately, Lebanon is one of the countries facing major problems to meet the demand for electricity, especially with the current overload of the population added to the big wave of migration of Syrian population due to the politic crisis in 2011 as well the current economic crisis that is devastating the country after the revolution of October 17, 2019 and the numerous explosions that have affected Beirut. Hence, the need to invest in new green power technologies such as photovoltaic (PV) panels and wind turbines.

PV panels are semiconductors-based materials with a very wide range of applications, particularly in the field of space applications and energy production. Electricity generation projects are being developed in many countries lacking fossil fuel reserves. In Morocco, the latest project was launched in 2018 with a photovoltaic system and a concentrating solar power (CSP) system to add two $400 \mathrm{MW}$ of combined systems to the national power supply [1]. PV panels include the traditional silicon solar cell, usually in the form of a flat plate, which is affected by cloudiness, the sun position and the angle of incidence of sunlight; the more normal the sunlight becomes, the more efficient it is. The second generation is a thin-layer of solar cells, made from amorphous silicon and non-silicon materials, and finally, there is the third generation of solar cells using a combination of amorphous silicon wafers and conductive materials. A study has shown that Lebanon has good average solar irradiation, producing a highly significant amount of power. The months of May to August are the most favorable, with a peak in July at more than $300 \mathrm{kWh} / \mathrm{m}^{2}$ per month [2]. With such promising data, the third type of PV seems to be suitable for use.

Similarly, wind power technology, which is technically a form of solar energy is becoming increasingly essential in the production of green energy, particularly in Canada, the United States, and Europe. For instance, a $10 \mathrm{GW}$ package of wind power has been installed in Canada since 2000, with 137 MW of installed capacity remaining in service worldwide. Consequently, Canada can eventually produce $100 \%$ of electricity from zero emission sources [3].

Hybrid PV solar/wind energy conversion systems have been widely used for electricity supply in isolated locations, far from the grid or distribution system. These systems provide reliable service and can operate for long periods of time [4]-[8]. Recently, Dursun et al. [9] performed a study of a hybrid PV-wind system in which they investigated the possibility of providing electricity to a remote location without any electrical connection, in the city of Edirne, Turkey. They found that the PV/wind/diesel system with battery can be widely used to replace or upgrade the existing stand-alone diesel system. In addition, a $25 \%$ saving was achieved by using the hybrid system compared to the stand-alone diesel system. Rehman and Sahin [10] carried out a study in Saudi Arabia using hybrid PV/wind system for water pumping in remote areas. They proved the feasibility of such a system by pumping water continuously throughout the year at a reasonable cost.

On the other side, a techno-economic feasibility study of a hybrid wind/solar power generation system (PGS) is being conducted by Chong et al. [11]. The results showed that the system can cover a significant part of a building energy demand and improve its independence from the urban electricity grid. Another study is performed by Kouhestani et al. [12] at the University of Lethbridge in Canada. A comparison of the resulting output of solar PV and wind turbine generation over 5 years with the university's electrical demand revealed that wind turbine and solar PV systems together could produce more than 3.6 times of the annual electricity consumption on average. Moreover, Nijhawan and Jianu [13] proved in a very recent study performed in Northern Ontario, Canada, that the PV/wind/hydrogen PGS can replace the conventional fuel-based system. This clean energy using renewable sources will replace the antiquated methods of power generation that pollute the environment and deplete the planet of its natural resources. A similar study was performed in Bahrain by Haji et al. [14] where they inaugurated the country's first hybrid renewable energy system (HRES) as a demonstration project. The authors found that the HRES supplied 50\% of the power demand with a reduction of $48 \%$ of $\mathrm{CO}_{2}$ gases emission.

In Lebanon, the amount of electricity produced does not meet energy needs. Thus, the necessary energy is either purchased from Syria or produced using the Turkish power ship and more recently, Diesel generators in each village. All these sources of energy mean that Lebanon suffers as much as any developing country from high greenhouse gas emission and $\mathrm{CO}_{2}$ emission rate. Without forgetting the severe energy crisis, ageing power infrastructure and the vulnerability of the electricity grid to extreme weather conditions due to the global warming. Therefore, to face this crisis, and for the first time in Lebanon, a solar/wind hybrid PGS is being designed to be implemented at the coastal highways [15].

This system is totally environmentally friendly as it is designed to produce green energy without any toxic gases emission such as carbon dioxide and nitrogen monoxide [16]. As well, there is no need to store the energy produced in batteries, also considered as a source of pollution since the electricity produced will be supplied directly to the grid utilities. Moreover, this system will be implemented at the middle of the 
highways, a governmental property, which eliminates the high cost of land. These two points are the strength of this research as they will save on the exhaustive costs of storage and land.

The remainder of the paper is structured as: section 2 deals with the methodology followed in the design of the PGS. The design of the PGS is presented in details in section 3. The average coastal wind speed is measured first as it is a crucial element of the design. In addition, the output power is also calculated in this section. Section 4 is devoted to an assessment of the project using RETScreen software. The project payback, the GHG and $\mathrm{CO}_{2}$ emissions, as well the annual income over the project lifetime are calculated. Finally, section 5 draws the main findings of the paper and tackles the future works.

\section{RESEARCH METHOD}

\subsection{Land use}

Building a carbon-free future is the most challenging and crucial topic facing the world today. That's why researchers are turning to green energy sources, where solar energy-relatively affordable and widely available-is sees as the most attractive. However, this alternative solution would have to overcome several obstacles to be considered as promising as one might imagine. One of these obstacles is the space required for the installation of a large station. Since 2006, the price of land in Lebanon has increased exponentially. This issue urges for finding unused government land where the design can be established and subsequently implemented. This is the idea of the highways where a snake shape of PV panels with a vertical wind turbine can be installed at the middle. These can be installed along the concrete blocks separating the highways into 2-ways. The idea can be imitated along any highway in Lebanon or elsewhere in neighboring countries.

In this project, the design took into consideration the highways between Tyre and Tripoli (as shown in Figure 1) where the total distance was measured to be 117000 meters without any type of obstacles intercepting the installation of the system such as bridges and publicity panels. This distance is $2 \mathrm{~m}$ wide allowing the installation of two rows of PV panels.

One acre of land is approximately about $4,046.856 \mathrm{~m}^{2}$, and the proposed PGS has an effective area of installation of $234,000 \mathrm{~m}^{2}$, which is equivalent approximately to 58 acres of land. On average, the price of an acre in the coastal region at Lebanon is approximately $400 \mathrm{k} \$$. Thus, the land cost would be $23 \mathrm{M} \$$. The installation of the PGS in the middle of highways will eliminate the cost of land. This is a significant reduction in the cost of systems in general.

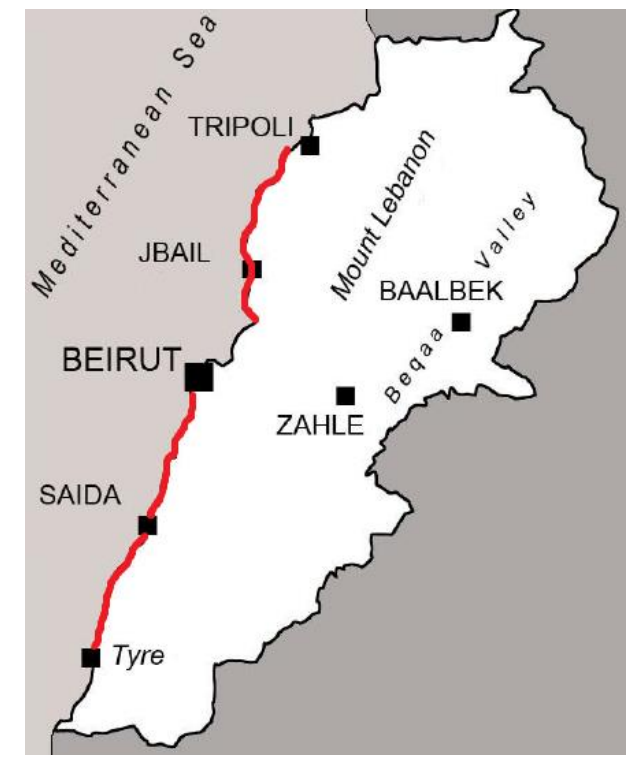

Figure 1. Map of the region where the PGS will be implemented (red highlighted)

\subsection{Battery storage}

Over the past two decades, batteries have moved from being the main catalyst for solar PV to be a marginal technology. Battery-based systems account for only $1 \%$ of annual PV installations in the U.S. and worldwide [17]. The objective of this evolution is simple. Grid-connected PV systems have practically high

Techno-economic study of a hybrid power generation system at the Lebanese ... (Mohammad Hammoud) 
productivity and almost unlimited capacity and require low maintenance over their lifetime. Furthermore, the off-grid (battery reinforcement PV frameworks) discharge $30 \%$ or more of the solar energy in the charge/release process, as shown in Figure 2(a). In addition, the off grid rejects all excess solar energy once the batteries are fully charged on a good summer day, as shown in Figure 2(b). The excess summer energy will be wasted. With a battery system, there is simply no way to save excess summer energy for winter use. Typically, a battery system is sized to conserve energy for few days on the worst solar day of the year in Lebanon (December). The solar power available at that time is about half of what we get in the summer per day [18].

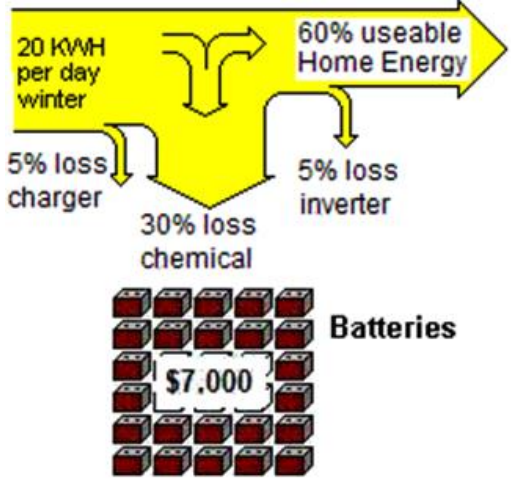

(a)

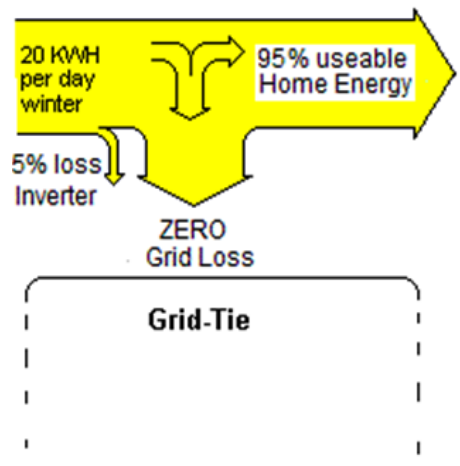

(b)

Figure 2. (a) Battery back-up vs (b) Grid-tie PV systems [17]

One of the principles selling points of solar power was power saving. This diminishes dependence on coal fueled generators, implying that most of the power utilized would be 'green'. Battery permits to store the abundance of energy produced during day, and subsequently utilized during top periods and during night. This is one of the many reasons that battery innovation has become more well known over the recent years. Battery integration into a solar plant, can serve against the decrease in power return from network and interruption of power during non-sunny hours. This renders the power system more stable and reliable. In many recent papers, it was proved that Batteries integration in a power system can successfully lessen oscillations in frequency and tie-line power profiles caused by small load disturbances, i.e. improve the stability and transient behavior of the system [19]. Regardless of all the previously mentioned benefits, a major drawback of implementing battery storage systems is still the initial cost, which could stop a project before it starts. In addition to this, the project aims to fulfill some demand in power usage during the day, and relying on wind turbines to complement the system during windy days (non-sunny).

The possibility to connect the proposed system to the national electricity grid through appropriate inverters, and to avoid the use of batteries, is another economic advantage of this system. In this way, the exhaustive cost of batteries and their maintenance is eliminated, with a good environmental impact due to the elimination of the chemical source inside the batteries.

\section{DESIGN}

The project design involves several steps including the actual measurements of average wind speed, which are carried out at the outset. Depending on the value of the wind speed and the availability on the Lebanese market, the wind turbine will be selected. In this section, all the details regarding the PV panels to be used, the steel frame that will support the design and the inverters to be installed to transform direct current DC into alternating current AC will be provided.

\subsection{Wind velocity}

Wind speed was measured on the coastal highway using a flowmeter located one meter above the road. Figure 3 shows the variation in wind speed (in m/s) for the period from 29 March to 24 April 2020. The complete analysis of the collected data showed an average wind speed of $4.1 \mathrm{~m} / \mathrm{s}$. This value is adapted to the energy production of the vertical axis wind turbine. Note that this the average value of the wind speed is backed up by RETScreen software [19] where the average value over the 12 months of the year at the coastal regions ranged between $4 \mathrm{~m} / \mathrm{s}$ and $4.5 \mathrm{~m} / \mathrm{s}$. 


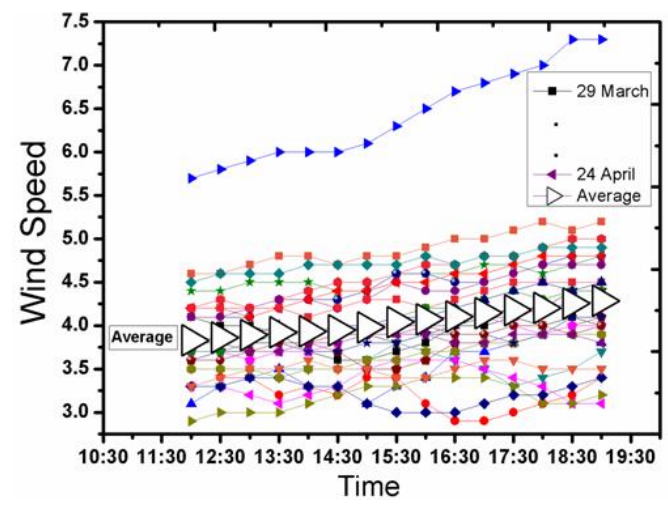

Figure 3. Wind speed at the coastal highway measured over one month

\subsection{PV panels and wind turbines}

A 300-watt polycrystalline panels were chosen for the design. These panels have the highest power rate among the other PV panels on the Lebanese market. During installation, the PV modules will be tilted by $24^{\circ}$ using a steel frame and directed southward, which is the case for optimal energy production in the coastal area as it can be concluded from the database of the RETScreen software [20] where the average solar irradiation ranged between 4 and $7 \mathrm{kWh} / \mathrm{m}^{2} /$ day over the year. As previously mentioned, the PV farm will cover 117000 meters from Tyre to Tripoli, with a width of 2 meters. The design consists of 87750 PV panels divided into two parallel lines of 43875 panels. These lines are in the middle of the highway. The shadow effect between consecutive PV panels, which can reduce the output power of the whole system, was taken into consideration. This problem was avoided by taking a shadow distance of $0.9 \mathrm{~m}$ between 2 consecutive PVs [15].

As far as the turbines are concerned, the type to be used is the Savonius type, with 1-meter height and 1-meter diameter, produced from materials with a high strength-to-weight ratio. Note that the Savonius vertical-axis wind turbine (VAWT) is a slow rotating, high torque machine with at least two blades and is used in low efficiency, high reliability power turbines. The type to be used has multiple semicircular shaped blades distributed around a vertical pole. It has a simple structure, great starting characteristics, generally low operating speeds and the capacity to catch wind from any direction. The turbines should be placed under the frame with a distance of 4 meters to avoid turbulence [21]. Thus, over a length of $117000 \mathrm{~m}$ length of the PGS, the number of VAWTs would be 29250.

\subsection{Steel frame and structural analysis}

The combined system of photovoltaic panels and wind turbines will be mounted on a steel frame manufactured based on numerical simulations to sustain extreme load values. The PV panels, as mentioned above, will have 87750 PVs placed on the steel frame over the entire costal distance of $117000 \mathrm{~m}$ and a width of 2 meters. An illustration of the combined system using CAD software is shown in Figure 4. The steel frame presented in Figure 4 consists of many geometries, starting with hollow square connecting fixture and an L-shaped corner bar. These are well galvanized in order to resist bending, corrosion, or any type of defect.

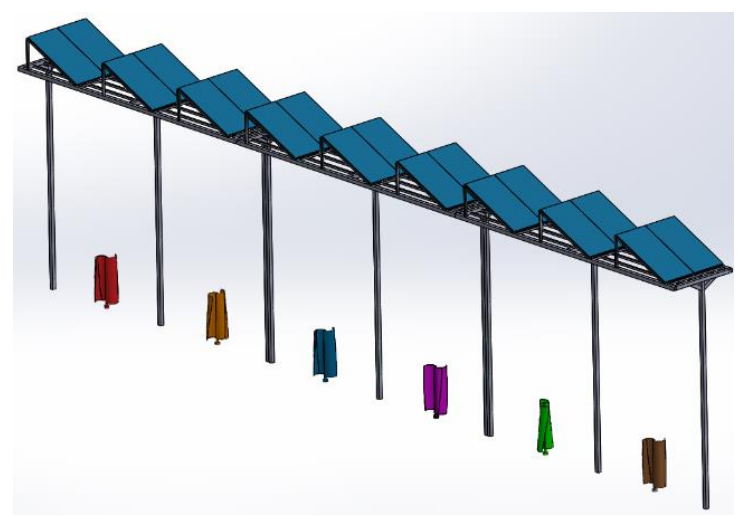

Figure 4. An insight of the system combining PV panels and wind turbines 
The structure was analyzed using finite element software to test the reliability of the steel frame. The wind speed was assumed at a high value of $120 \mathrm{~km} / \mathrm{h}$. Results depicted in Figure 5 show that the maximum stress is $5.11 \mathrm{MPa}$, a value much lower than the yield tensile of the steel. Thus, the system is considered completely safe against elastic deformation.

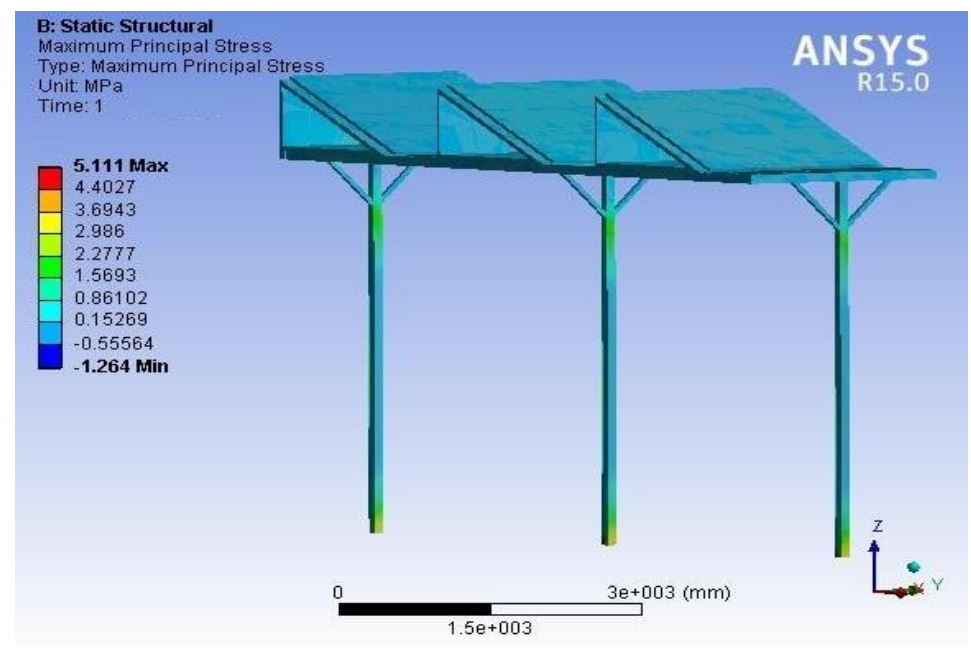

Figure 5. Maximum principal stress at $120 \mathrm{~km} / \mathrm{h}$ (extreme wind speed during winter season)

\subsection{Inverters}

There are several types of inverters, such as: central, string, and micro. The central inverter is the most used and the most reliable. The choice of the inverter depends on the application for which it is used. In the designed snake-system, central inverters cannot be implemented and that's due to a combination of a large PV array which will lead to a high voltage drop in the wires. This therefore leaves two inverter options: string or micro. For the current design, the micro inverter seems to be the most applicable yet not the cheapest. All panels will have the micro-inverter backed up. The advantage here, comes in more output power for each panel (about 5-25\%), the problem in one of the cells (shading for example) will not affect the whole system as in other types of inverters. This doesn't add simplicity to the design in addition to the higher cost compared to others in the family, yet, looking at the longer lifespan for micro-inverters (15-25 years compared to 5-10 years for other types), this comes to be an advantage on long term than being a disadvantage.

\subsection{PV power output}

Hereafter, the total power that can be generated by the current design is calculated. The nominal peak power that can be generated with the selected PV panel is $300 \mathrm{~W}$, which is, a total of $87,750 \times 300=26.325 \mathrm{MWh}$ nominal PV power generated. In a recent study performed in Lebanon [22], the annual average energy generated by a PV panel is $387 \mathrm{kWh} /$ year, which means that for 87,750 panels, a total of $34 \mathrm{GW}$ per year is produced. For the VAWT, the maximum power generated by each turbine is calculated using (1).

$$
P_{t}=\frac{1}{2} \rho C_{p} A V^{3}
$$

where $\rho$ is the density of the air, A is the swept area of the turbine perpendicular to the flow direction, $\mathrm{V}$ is the wind velocity, and $C_{p}$ is the power coefficient.

The value of the air density at the coast is $\rho=1.225 \mathrm{~kg} / \mathrm{m} 3, C_{p}$ is taken at its maximum value of

$C_{p}=\frac{16}{27}$, the average wind speed was measured at $4.1 \mathrm{~m} / \mathrm{s}$, and the swept area is the height of the blades times the rotation diameter which equals $1 \mathrm{~m}^{2}$. Replacing these values into (1), the maximum output power of the VAWT is $25 \mathrm{Wh}$. Thus, the full power produced by 29,250 VAWT is equal to $P=25 \times 29,250=$ $0.732 \mathrm{MWh}$. Taking into consideration that the various power losses are estimated to $9 \%$, the VAWTs can generate an annual energy of $P=5.88 \mathrm{GW}$ per year. Regarding the global design, the resulting capacity of the solar/wind PGS is estimated to $39.9 \mathrm{GW}$ per year. 


\section{RESULTS AND DISCUSSION}

Tools and software to guide energy choices include hybrid optimization model for renewable electricity, hybrid designer, and RETScreen expert. The RETScreen expert software is recently used in this type of hybrid systems. The software is a package developed by the Government of Canada. It was released to the public on September 2016. It allows to identify, evaluate and optimize the technical and financial viability of potential renewable energy, energy efficiency and cogeneration projects. Several studies were performed to validate the techno-economic and environmental sustainability of PV and wind technologies [20], [23].

Using RETScreen expert software, it was found that the proposed hybrid PGS has an estimated initial cost of approximately 31.4 M\$, and with 25-years lifetime, the system would have produced electricity at a cost of approximately $80.6 \mathrm{M} \$$ which is roughly 2.6 times the actual system cost. The initial cost for the main component of the system (PV modules and wind turbines) as well as inverter installation in addition to the electric export revenue (\$) are shown in Figure 6.

\begin{tabular}{|c|c|c|c|}
\hline \multicolumn{4}{|l|}{ Electricity export revenue } \\
\hline Electricity exported to grid & & $\mathrm{MWh}$ & 39,905 \\
\hline Electricity export rate & & $\$ / k W h$ & 0.10 \\
\hline Electricity export revenue & & $\$$ & $3,990,548$ \\
\hline Electricity export escalation rate & & $\%$ & $2 \%$ \\
\hline \multicolumn{4}{|l|}{ Costs | Savings | Revenue } \\
\hline \multicolumn{4}{|l|}{ Initial costs } \\
\hline Initial cost & $100 \%$ & $\$$ & $31,443,750$ \\
\hline Total initial costs & $100 \%$ & $\$$ & $31,443,750$ \\
\hline Incentives and grants & & $\$$ & 0 \\
\hline \multicolumn{4}{|l|}{ Annual costs and debt payments } \\
\hline O\&M costs (savings) & & $\$$ & 561,600 \\
\hline Total annual costs & & $\$$ & 561,600 \\
\hline \multicolumn{4}{|l|}{ Annual savings and revenue } \\
\hline Electricity export revenue & & $\$$ & $3,990,548$ \\
\hline Total annual savings and revenue & & $\$$ & $3,990,548$ \\
\hline
\end{tabular}

Figure 6. Project cost and electricity export revenue from RETScreen expert

In addition, Figure 7 presents the financial viability where the internal rate of return (IRR) is the annual rate of growth an investment is expected to generate. The higher an IRR is, the more desirable an investment is to undertake. Moreover, the net present value (NPV) is the difference between the present value of cash inflows and the present value of cash outflows over a period. If the NPV of a project or investment is positive, this means that the discounted present value of all future cash flows related to that project or investment will be positive, and therefore more attractive which is the case of this project.

Financial viability
\begin{tabular}{|lcr|}
\hline Pre-tax IRR - equity & $\%$ & $12.1 \%$ \\
Pre-tax IRR - assets & $\%$ & $12.1 \%$ \\
Simple payback & $\mathrm{yr}$ & 9.2 \\
Equity payback & $\mathrm{yr}$ & 8.3 \\
Net Present Value (NPV) & $\$$ & $9,014,769$ \\
Annual life cycle savings & $\$ / \mathrm{yr}$ & 917,760 \\
Benefit-Cost (B-C) ratio & & 1.3 \\
Energy production cost & $\$ / \mathrm{kWh}$ & 0.097 \\
\hline
\end{tabular}

Figure 7. Financial viability from RETScreen

Techno-economic study of a hybrid power generation system at the Lebanese ... (Mohammad Hammoud) 
Figure 8 provides a summary of the payback period of the project. In addition, the system would result in a net decrease of $\mathrm{CO}_{2}$ and GHG flows of $\sim 28,211 \mathrm{tCO} /$ year as shown in Figure 9 and $\sim 705,27 \mathrm{tCO}_{2}$ over life of the system. A comparison between the proposed case and the base one (fuel-based) shows a reduction of $93 \%$ of GHG emissions.

Finally, implementing this project would help surely in reducing the effect of global warming caused by burning the fuel to produce the same amount of energy in this region. The project GHG emission reduction of $\sim 28,211 \mathrm{tCO}_{2}$ /year is equivalent to 2,594 ha of forest absorbing carbon not cut down over 1 year of the entire life span of the project if installed.

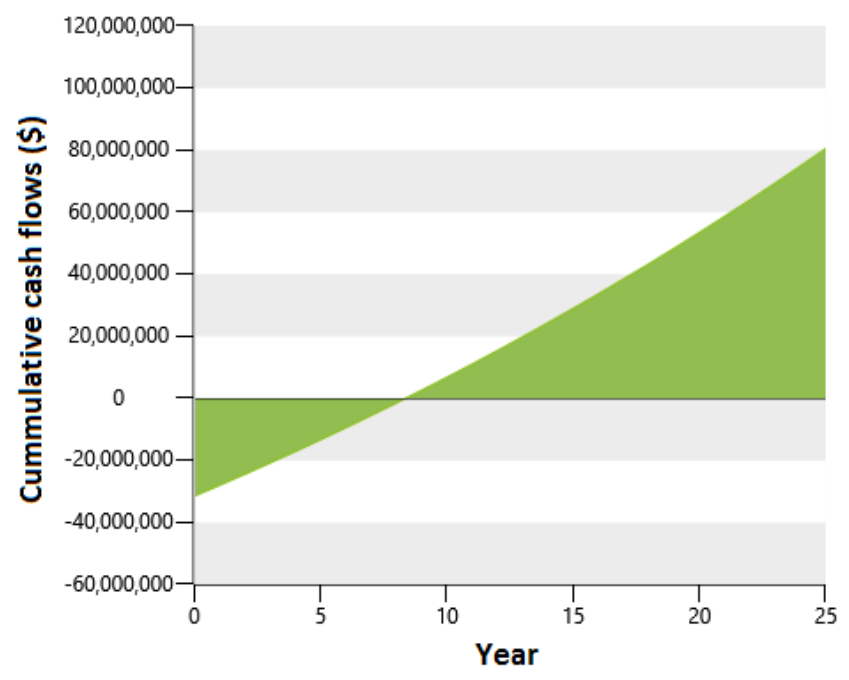

Figure 8. Payback period of the hybrid PGS calculated using RETScreen

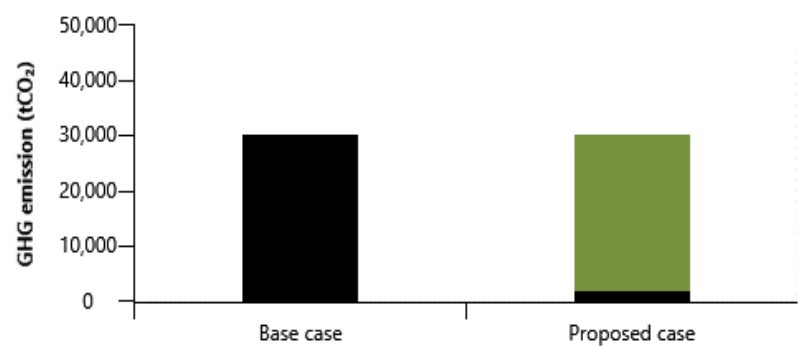

Figure 9. Gross annual GHG emission reduction

\section{CONCLUSION}

The work presented in this paper is an important step in the development of the country powered by green energy and it is in the hands of the Lebanese government to produce electrical energy from renewable sources, especially when it is installed in the middle of the coastal highway to lighten the roads and to cover other needs from Tyre to Tripoli on 117,000 meters at zero cost over time. The project grid connected, feeds electricity directly into the power grid, saving the high cost of the storage system. Additionally, the land cost is zero, since it is installed on public land, which will cost nearly $23 \mathrm{M} \$$, although the overall initial project cost is no more than $31.4 \mathrm{M} \$$. The overall annual energy generated from the system is $39.9 \mathrm{GW} /$ year. With an annual total of $34 \mathrm{GW} /$ year generated by the photovoltaic panels and $5.9 \mathrm{GW} /$ year by the turbines at an average wind speed of $4.1 \mathrm{~m} / \mathrm{s}$. The design is within the safety range regarding failures of any type or yielding it is made of high-strength materials. Furthermore, it is an environmentally friendly project, without gas emission, without effect on humans, animals and plants. This project provides, according RETScreen data, a net reduction of $\mathrm{CO}_{2}$ and GHG emissions of approximately 28,211 $\mathrm{tCO}_{2} /$ year. The payback period is estimated to 9 years over a 25 -years life span. The proposed design could be replicated on all highways in Lebanon other than the coastal region. Similarly, the same research approach could be applied to most Lebanese areas to ensure maximum use of unused land for grid-connected electricity generation. 


\section{REFERENCES}

[1] G. Frisari and M. Stadelmann, "De-risking concentrated solar power in emerging markets: The role of policies and international finance institutions," Energy Policy, vol. 82, no. 1, pp. 12-22, 2015, doi: 10.1016/j.enpol.2015.02.011.

[2] G. Hassan, "The national wind atlas of Lebanon," United Nations Development Program (UNDP), 2011.

[3] "Wind market," The Canadian Wind Energy Association (CanWEA). Accessed: Jul. 17, 2021. [Online]. Available: https://canwea.ca/wind-energy/national/.

[4] F. Ben M', hamed Chellali, A. Recioui, M. R. Yaiche, and H. Bentarzi, "A hybrid wind/solar/diesel stand alone system optimisation for remote areas in Algeria," International Journal of Renewable Energy Technology, vol. 5, no. 1, p. 12, 2014, doi: 10.1504/ijret.2014.059658.

[5] A. Recioui and K. Dassa, "Design of standalone micro-grid systems using teaching learning based optimization," Algerian Journal of Signals and Systems, vol. 2, no. 2, pp. 75-85, Jun. 2017, doi: 10.51485/ajss.v2i2.34.

[6] R. Qonain, M. Rafi, I. Khan, and S. Sageer, "Ecological and economical friendly analysis of a hybrid solar-griddiesel connected power generation system," International Journal of Applied Power Engineering (IJAPE), vol. 7, no. 1, p. 1, Apr. 2018, doi: 10.11591/ijape.v7.i1.pp1-9.

[7] Q. W. Ali, M. Aamir, A. Nawaz, Z. Udin, and S. Ullah, "Implementation of hybrid generation power system in Pakistan," International Journal of Applied Power Engineering, vol. 3, no. 2, pp. 75-81, 2014.

[8] Q. W. Ali, M. Aamir, A. Nawaz, Z. Udin, and S. Ullah, "Hybrid Generation Power System for Domestic Applications," International Journal of Applied Power Engineering, vol. 3, no. 2, pp. 82-89, 2014

[9] B. Dursun, C. Gokcol, I. Umut, E. Ucar, and S. Kocabey, "Techno-economic evaluation of a hybrid PV - Wind power generation system," International Journal of Green Energy, vol. 10, no. 2, pp. 117-136, Jan. 2013, doi: 10.1080/15435075.2011.641192.

[10] S. Rehman and A. Z. Sahin, "A wind-solar PV hybrid power system with battery backup for water pumping in remote localities," International Journal of Green Energy, vol. 13, no. 11, pp. 1075-1083, Sep. 2016, doi: $10.1080 / 15435075.2012 .729169$

[11] W. T. Chong, M. S. Naghavi, S. C. Poh, T. M. I. Mahlia, and K. C. Pan, "Techno-economic analysis of a windsolar hybrid renewable energy system with rainwater collection feature for urban high-rise application," Applied Energy, vol. 88, no. 11, pp. 4067-4077, Nov. 2011, doi: 10.1016/j.apenergy.2011.04.042.

[12] F. Mansouri Kouhestani, J. Byrne, L. Spencer, P. Hazendonk, B. Brown, and D. Johnson, "A comprehensive assessment of solar and wind energy potential at the University of Lethbridge campus, a medium-sized western Canadian university," International Journal of Green Energy, vol. 16, no. 14, pp. 1246-1263, Nov. 2019, doi: 10.1080/15435075.2019.1671400.

[13] M. Nijhawan and O. A. Jianu, "Investigation of sustainable energy alternatives for powering remote communities in northern Ontario," International Journal of Green Energy, vol. 17, no. 8, pp. 467-475, Jun. 2020, doi: $10.1080 / 15435075.2020 .1763354$.

[14] S. Haji, M. Bin Shams, A. S. Akbar, H. Abdali, and A. Alsaffar, "Energy analysis of Bahrain's first hybrid renewable energy system," International Journal of Green Energy, vol. 16, no. 10, pp. 733-748, Aug. 2019, doi: 10.1080/15435075.2019.1619567.

[15] M. Hammoud et al., "Power from photovoltaic installed in the middle of the Lebanese high-ways: PV system in the middle of the high-ways," in 20163 rd International Conference on Renewable Energies for Developing Countries, REDEC 2016, Jul. 2016, pp. 1-4, doi: 10.1109/REDEC.2016.7577552.

[16] H. Farzaneh, B. McLellan, and K. N. Ishihara, "Toward a CO2 zero emissions energy system in the Middle East region," International Journal of Green Energy, vol. 13, no. 7, pp. 682-694, May 2016, doi: $10.1080 / 15435075.2014 .889014$.

[17] B. Bruninga, "Solar - grid-tie or off-grid?" Accessed: Jul. 17, 2021. [Online]. Available: http://www.aprs.org/offgrid-maybe.html.

[18] "Photovoltaic solar panels - which type?" Accessed: Jul. 17, 2021. [Online]. Available: https://www.solarfacts.com/panels/panel-types.php.

[19] U. Datta, A. Kalam, and J. Shi, "Battery energy storage system for transient frequency stability enhancement of a large-scale power system," in 2017 Australasian Universities Power Engineering Conference, AUPEC 2017, Nov. 2018, vol. 2017-Novem, pp. 1-5, doi: 10.1109/AUPEC.2017.8282465.

[20] A. B. Owolabi, B. E. K. Nsafon, and J. S. Huh, "Validating the techno-economic and environmental sustainability of solar PV technology in Nigeria using RETScreen Experts to assess its viability," Sustainable Energy Technologies and Assessments, vol. 36, p. 100542, Dec. 2019, doi: 10.1016/j.seta.2019.100542.

[21] C. M. Jang, Y. G. Kim, S. K. Kang, and J. H. Lee, "An experiment for the effects of the distance and rotational direction of two neighboring vertical Savonius blades," International Journal of Energy Research, vol. 40, no. 5, pp. 632-638, Apr. 2016, doi: 10.1002/er.3454.

[22] "Solar insolation irradiance Lebanon," SCRIBD. Accessed: Jul. 17, 2021. [Online]. Available: https://fr.scribd.com/document/325116399/Solar-Insolation-Irradiance-Lebanon.

[23] Y. Himri, M. Merzouk, N. Kasbadji Merzouk, and S. Himri, "Potential and economic feasibility of wind energy in south West region of Algeria," Sustainable Energy Technologies and Assessments, vol. 38, p. 100643, Apr. 2020, doi: 10.1016/j.seta.2020.100643. 


\section{BIOGRAPHIES OF AUTHORS}
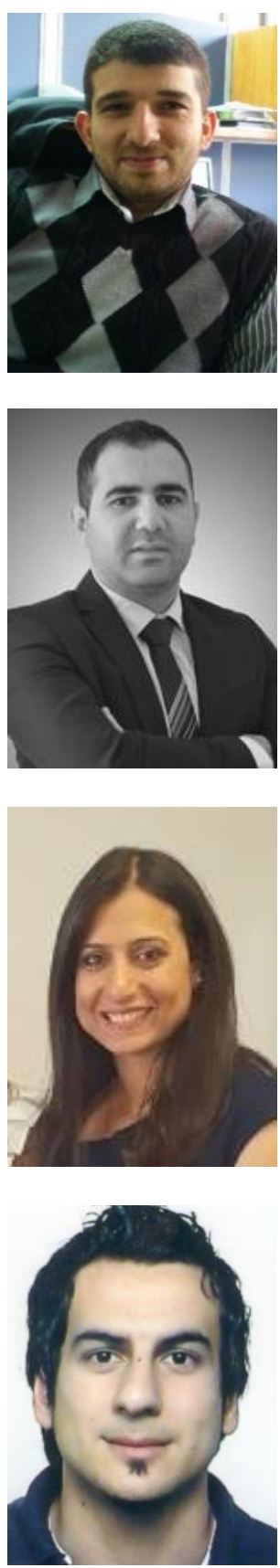

Mohammad Hammoud is an Associate Professor at the Lebanese International University, department of Mechanical Engineering, Beirut, Lebanon. He received his $\mathrm{PhD}$ in Solid Mechanics and Materials from Ecole Nationale de Ponts et Chaussées (ENPC) in 2009, Paris, France. Masters in Materials and Manufacturing Process from the Ecole Nationale Supérieure d'Arts et Métiers (ENSAM) in 2006, Paris, France. Diploma in Mechanical Engineering from the Lebanese University in 2005, Beirut, Lebanon. Research interests: vibration control, energy management in electronic devices and PV modules, and renewable energy.

Jaafar Hallal is an Assistant Professor of Solid Mechanics in the Lebanese University, Faculty of Engineering and the International University of Beirut. He obtained his Ph.D. in Electromechanical Engineering in 2014 and his Master in Mechatronics Systems in 2011 from the Sorbonne Universités, Université de Technologie de Compiègne, France, and his Mechanical Engineering diploma in 2011 from the Lebanese University, Faculty of Engineering, Lebanon. Research interests: combined vibro-acoustic and electromagnetic model of electric machine considering the uncertainties originated from the material and geometrical properties, and new measurements technics.

Tala Moussa is an Assistant Professor at the University of Reims Champagne Ardennes, France. Research: Matim Group, University of Reims Champagne Ardennes, France. (Building Physics, Agromaterials, Renewable Energy, Heat Transfer). Teaching: ESIReims, the Engineering School from the University of Reims.

Hussein Kassem is an Associate Professor at the Lebanese International University, at the department of Electrical Engineering, Beirut, Lebanon. He received his B.S. degree in Electronics in 2003 from the Lebanese university, Faculty of sciences, Beirut, Lebanon, his M.S. degree in Electronics and high-frequency devices for communication systems in 2005 from the University of Bretagne Occidental, Brest, France, and his Ph.D. in Electronics in 2009 from University of Bordeaux, Bordeaux, France. Since 2005, Hussein kassem worked in many related engineering fields. Research interests: microwave devices, dielectric material, characterization and dielectric constant measurements, non-destructive measurements, and thin films ferroelectric materials. 